\title{
Propriedades físicas de filmes comestíveis a base de proteínas miofibrilares de carne bovina
}

\section{Physical properties of edible films based on bovine myofibril proteins}

\author{
Sílvia Maria Almeida de Souza ${ }^{1 *}$; Paulo José do Amaral Sobral²; \\ Florencia Cecilia Menegalli ${ }^{3}$
}

\begin{abstract}
Resumo
As proteínas miofibrilares têm excelentes propriedades filmogênicas. O objetivo deste artigo foi o estudo do efeito do tratamento térmico, do $\mathrm{pH}$ e da concentração de plastificante $(\mathrm{Cp})$ da solução filmogênica (SF) a base de proteínas miofibrilares liofilizadas (PML) extraídas de músculo bovino empregandose a técnica de solubilização por soluções salinas diluídas, sobre algumas propriedades físicas dos filmes comestíveis, utilizando-se uma metodologia de superfície e resposta (MSR). Os filmes foram elaborados a partir de SF contendo $1 \mathrm{~g}$ de PML/100 g de SF, e de Cp-50 a $75 \mathrm{~g}$ de glicerol/100 g de PML. A PML era dispersa em água sob agitação moderada, e o pH era mantido entre 2,5-3,5 com o emprego de ácido acético. As SF foram submetidas a tratamentos térmicos em diferentes temperaturas $\left(35-75^{\circ} \mathrm{C}\right)$, por 45 minutos. Os filmes foram secos em estufa com circulação forçada de ar a $37^{\circ} \mathrm{C} / 18 \mathrm{~h}$, condicionados em $75 \%$ de umidade relativa, a $25^{\circ} \mathrm{C} / 48 \mathrm{~h}$, antes da realização de análises: propriedades mecânicas - teste de perfuração; opacidade aparente por espectrofotometria; solubilidade, por imersão em água; e permeabilidade ao vapor de água, pelo método gravimétrico. Em geral, os filmes se apresentaram com boa aparência, translúcidos, de fácil manuseio e tátil, exceto para os filmes formados em $\mathrm{pH} 2,5$ e em temperatura $\left(35^{\circ} \mathrm{C}\right)$, com espessura média de $0,040 \pm 0,005 \mathrm{~mm}$. O pH da SF afetou significativamente todas as propriedades físicas estudadas. A temperatura do tratamento térmico da SF afetou significativamente a força na ruptura, solubilidade e a permeabilidade ao vapor de água (Pva). Esse tratamento pode favorecer as interações intermoleculares via formação de pontes dissulfídicas, mas um tratamento muito intenso pode reverter esse efeito por alterações estruturais irreversíveis nas proteínas. A Cp afetou significativamente todas as propriedades estudadas, com exceção da opacidade aparente. O plastificante aumenta a mobilidade das macromoléculas, reduzindo suas interações, com conseqüências em todas as propriedades físicas.
\end{abstract}

Palavras-chave: Propriedades mecânicas, permeabilidade ao vapor de água, solubilidade, opacidade, superfície de resposta

\begin{abstract}
Myofibril proteins have excellent filmogenic properties. The objective of this article was to study the effect of the thermal treatment, of the $\mathrm{pH}$ and of the plasticizer concentration $(\mathrm{Cp})$ of the filmogenic solution (FS), using over some physical properties of edible films, using a surface and response
\end{abstract}

\footnotetext{
${ }^{1}$ Prof $^{\text {a }}$ do Dept ${ }^{\mathrm{o}}$ de Tecnologia, Colegiado de Engenharia de Alimentos, Universidade Estadual de Feira de Santana, UEFS. Av. Transnordestina s/n, Novo Horizonte CEP: 44036-900, Feira de Santana, BA. E-mail: ss almeida@yahoo.com.br

2 Prof. do Dept ${ }^{\circ}$ de Engenharia de Alimentos, Faculdade de Zootecnia e Engenharia de Alimentos, Universidade de São Paulo, USP. Av. Duque de Caxias Norte, 225. CEP: 13635-900, Pirassununga, SP. E-mail: pjsobral@usp.br

${ }^{3}$ Prof $^{\mathrm{a}}$ do Dept $^{\mathrm{o}}$ de Engenharia de Alimentos, Faculdade de Engenharia de Alimentos, Universidade Estadual de Campinas, UNICAMP. C P 6121, CEP: 13830-970, Campinas, SP. E-mail: fcm@fea.unicamp.br

*Autor para correspondência
} 
methodology (SRM). Films were made of lyophilized myofibril proteins (LMP) extracted from bovine muscle, employing the technique of solubility obtained from diluted saline solutions. The films were elaborated from FS containing $1 \mathrm{~g}$ of LMP/100g of FS and from Cp of $50 \mathrm{~g}$ to $79 \mathrm{~g}$ of glycerin/100 $\mathrm{g}$ of LMP. The LMP was dispersed in water under moderate agitation, and the $\mathrm{pH}$ was kept at 2.5-3.5 with the use of acetic acid. The FS were submitted to thermal treatment at different temperatures for 45 minutes. Films were dried in ventilated oven at $37^{\circ} \mathrm{C} / 18 \mathrm{hr}$, conditioned at $75 \%$ of relative humidity at $25^{\circ} \mathrm{C} / 48$ $\mathrm{hr}$ before analysis of: mechanical properties by puncture test; apparent opacity by spectrophotometer; solubility by immersion in water; and water vapor permeability by the gravimetric method. In general, films showed good appearance, translucent, easily handled and touchable, except for the films formed with $\mathrm{pH} 2.5$ and at a low temperature $\left(35^{\circ} \mathrm{C}\right)$, with a medium thickness of $0.400 \pm 0.005 \mathrm{~mm}$. The $\mathrm{pH}$ of the FS significantly affected all the physical properties under study. The temperature of the thermal treatment of the FS greatly affected the force at the rupture, solubility and water vapor permeability. This treatment can promote intermolecular interactions through the formation of disulphide bonds; however a very intense treatment can reverse this effect by irreversible structural alterations in the proteins. The glycerol concentration affected considerably all the properties under study, with the exception of the apparent opacity. Plasticizer increases the mobility of macromolecules with consequences in all physical properties.

Key words: Mechanical properties, water vapor permeability, solubility, opacity, surface response

\section{Introdução}

Em meados dos anos 90, Cuq et al. (1995) demonstraram que as proteínas miofibrilares, mais precisamente de Sardinhas do Mediterrâneo, têm excelentes propriedades filmogênicas, isto é, sob certas condições de tratamento térmico, e sobretudo de $\mathrm{pH}$, essas proteínas seriam capazes de formar uma matriz contínua, sendo possível assim, a produção de material fino e flexível, ou seja, de filmes flexíveis. Na seqüência, esse grupo de pesquisadores realizou vários estudos para verificar o efeito da espessura, $\mathrm{pH}$, concentração de proteína e/ou de plastificante, na solução filmogênica, sobre diversas propriedades físicas e funcionais dos filmes (CUQ et al., 1996a,1996b; 1997a,1997b). Esses autores divulgaram, dentre outras coisas, a metodologia de preparo das proteínas a partir do músculo do peixe, que consistia basicamente na cominuição do músculo, seguida de várias etapas de lavagens com água, para remoção das proteínas sarcoplasmáticas, que além de serem de menores pesos moleculares, são responsáveis pelo odor característicos de pescados, e remoção das proteínas do estroma por simples passagem em peneiras selecionadas adequadamente.

Monterrey e Sobral (1999; 2000) utilizaram processo idêntico ao de Cuq et al. (1995) para preparar proteínas miofibrilares de músculo de Tilápia do Nilo. Esses autores também estudaram o efeito do $\mathrm{pH}$, concentração de proteínas e de plastificante sobre as principais características dos filmes preparados com as proteínas em questão. Dessa forma, não havia mais dúvidas sobre a capacidade filmogênica das proteínas miofibrilares produzidas por um simples processo de separação física das diversas frações das proteínas do músculo.

Estudos similares com proteínas miofibrilares do músculo bovino foram realizados por Sobral, Ocuno e Savastano Júnior (1998), Sobral (2000) e Sobral e Ocuno (2000), que então puderam demonstrar a capacidade filmogênica dessas proteínas. Os filmes dessas proteínas, em particular, apresentaram propriedades físicas similares aos filmes a base de proteínas miofibrilares de peixes, descritos anteriormente, com exceção da cor. Os filmes de proteínas miofibrilares de músculo bovino apresentaram coloração mais intensa que a dos filmes a base de proteínas miofibrilares de Tilápia do Nilo (SOBRAL, 2000), como conseqüência da presença de resíduos de mioglobina nas proteínas preparadas a partir de músculo bovino (OCUNO; SOBRAL, 1998), que conferiram uma coloração amarelada aos filmes. 
As boas propriedades físicas dos filmes a base de proteínas miofibrilares foram explicadas pelo alto peso molecular das proteínas e por terem grande potencial de ligações intra e intermoleculares (CUQ et al., 1995). Segundo Cheftel, Cuq e Lorient (1989), essas interações podem ser alteradas de acordo com o interesse tecnológico, via mudanças no $\mathrm{pH}$, por tratamento térmico, uso de aditivos, dentre outros. Dependendo da intensidade do tratamento térmico aplicado na solução formadora de filme, a proteína pode sofrer alterações estruturais, envolvendo a formação de pontes de enxofre entre cadeias peptídicas adjacentes, o que teoricamente, pode afetar as propriedades mecânicas dos filmes, e/ou simplesmente desnaturá-la irreversivelmente, o que pode afetar a permeabilidade e a solubilidade dos respectivos filmes (STUCHELL; KROCHTA, 1994). Além disso, há o fator $\mathrm{pH}$ que, normalmente, deve ser controlado para se garantir melhor solubilização das proteínas, uma vez que as proteínas miofibrilares são consideradas insolúveis em água (CHEFTEL; CUQ; LORIENT, 1989).

Em todos os estudos com proteínas miofibrilares de músculos de peixes ou de bovinos, descritos acima, as explicações sobre os comportamentos das propriedades físicas dos filmes foram feitas em termos dos parâmetros de produção das soluções filmogênicas. Procurando evitar efeitos devido a eventuais impurezas nas proteínas miofibrilares, Souza, Sobral e Menegalli (2004) realizaram um estudo sobre a extração e caracterização de proteínas miofibrilares de carne bovina, para o emprego na produção de filmes comestíveis. Os autores modificaram uma metodologia clássica de extração seqüencial de proteínas pelo emprego de soluções salinas diluídas, obtendo, nesse caso, filmes incolores, diferentemente ao observado no caso dos filmes com proteínas miofibrilares de músculo bovino, preparadas por simples separação de proteínas (SOBRAL, 2000).

Nesse contexto, o objetivo deste artigo foi o de estudar o efeito do tratamento térmico, $\mathrm{pH}$ e da concentração de plastificante da solução filmogênica a base de proteínas miofibrilares, sobre algumas propriedades físicas dos filmes comestíveis elaborados com aquelas proteínas, utilizando-se a metodologia de superfície e resposta (MSR). As proteínas foram extraídas de músculo bovino empregando-se a técnica de solubilização por soluções salinas diluídas, de acordo com Souza, Sobral e Menegalli (2004), sobre algumas propriedades físicas dos filmes comestíveis produzidos com aquelas proteínas, utilizando-se uma metodologia de superfície e resposta (MSR).

\section{Material e Métodos}

\section{Elaboração dos filmes}

Osfilmesforamelaboradosutilizando-seproteínas miofibrilares liofilizadas (PML), extraídas de carne bovina, de acordo com a metodologia descrita por Souza, Sobral e Menegalli (2004). A composição centesimal da PML foi a seguinte: proteínas, 84,3 $\pm 0,06 \%$; gordura, $4,9 \pm 0,02 \%$; sais minerais, 0,15 $\pm 0,01 \%$; cinzas, $7,4 \pm 0,03 \%$; e umidade, $3,0 \pm$ $0,05 \%$.

Os filmes foram elaborados a partir de soluções coloidais filmogênicas (SF) contendo $1 \mathrm{~g}$ de PML/100 g de SF, e de 50 a $75 \mathrm{~g}$ de glicerol/100 g de PML. A PML foi dispersa em água sob agitação moderada, e o pH foi mantido entre 2,5 e 3,5 com o emprego de ácido acético glacial (Merck, Alemanha). As SF foram submetidas a tratamentos térmicos em diferentes temperaturas $\left(35\right.$ a $\left.75^{\circ} \mathrm{C}\right)$, por 45 minutos, utilizando-se um banho-maria (Ultratermostático, Modelo 111, FANEM, Brasil). as SF foram aplicadas sobre suportes de acrílico e submetidas à secagem, em estufa com circulação forçada de ar a $37^{\circ} \mathrm{C} / 18 \mathrm{~h}$. A elaboração dos filmes seguiu um planejamento experimental fatorial 23 completo, conforme descrito na Tabela 1, que apresenta os valores das variáveis independentes, codificados e reais.

Os filmes, assim produzidos, foram condicionados, por $48 \mathrm{~h}$, em dessecadores 
contendo solução saturada de cloreto de sódio, que proporcionava ambiente com $75 \%$ de umidade relativa, a $25^{\circ} \mathrm{C}$.

\section{Planejamento experimental}

Uma metodologia de superfície e resposta (RSM) foi utilizada para análise dos efeitos dos seguintes parâmetros: concentração do plastificante, $\mathrm{Cp}$ (X1);
pH (X2) e temperatura, T (X3) (Tabela 1), sobre as propriedades mecânicas [força (Y1) e deformação (Y2) na ruptura], solubilidade (Y3), opacidade (Y4) e a permeabilidade ao vapor de água (Y5) dos filmes. Os valores das variáveis independentes foram calculados segundo um planejamento fatorial $2^{3}$ completo, com 4 repetições no ponto central (BARROS NETO; SCARMINIO; BRUNS, 2005).

Os valores das variáveis independentes, codificados e reais, estão apresentados na Tabela 1 .

Tabela 1. Planejamento experimental fatorial $2^{3}$ completo.

\begin{tabular}{cccc}
\hline $\mathrm{N}^{\circ}$ Experimento $^{\mathrm{a}}$ & \multicolumn{3}{c}{ Variáveis independentes } \\
\cline { 2 - 4 } & $\mathrm{X}_{1}(\mathrm{Cp})$ & $\mathrm{X}_{2}(\mathrm{pH})$ & $\mathrm{X}_{3}(\mathrm{~T})$ \\
\hline $01(16)$ & $55,06(-1)$ & $2,7(-1)$ & $43,09(-1)$ \\
$02(15)$ & $69,94(1)$ & $2,7(-1)$ & $43,09(-1)$ \\
$03(14)$ & $55,06(-1)$ & $3,3(1)$ & $43,09(-1)$ \\
$04(13)$ & $69,94(1)$ & $3,3(1)$ & $43,09(-1)$ \\
$05(12)$ & $55,06(-1)$ & $2,7(-1)$ & $66,90(1)$ \\
$06(11)$ & $69,94(1)$ & $2,7(-1)$ & $66,90(1)$ \\
$07(10)$ & $55,06(-1)$ & $3,3(1)$ & $66,90(1)$ \\
$08(09)$ & $69,94(1)$ & $3,3(1)$ & $66,90(1)$ \\
$09(05)$ & $50,00(-1,68)$ & $3,0(0)$ & $55,00(0)$ \\
$10(07)$ & $75,00(1,68)$ & $3,0(0)$ & $55,00(0)$ \\
$11(06)$ & $62,50(0)$ & $2,5(-1,68)$ & $55,00(0)$ \\
$12(08)$ & $62,50(0)$ & $3,5(1,68)$ & $55,00(0)$ \\
$13(18)$ & $62,50(0)$ & $3,0(0)$ & $35,00(-1,68)$ \\
$14(17)$ & $62,50(0)$ & $3,0(0)$ & $75,00(1,68)$ \\
$15(01)$ & $62,50(0)$ & $3,0(0)$ & $55,00(0)$ \\
$16(02)$ & $62,50(0)$ & $3,0(0)$ & $55,00(0)$ \\
$17(03)$ & $62,50(0)$ & $3,0(0)$ & $55,00(0)$ \\
$18(04)$ & $62,50(0)$ & $3,0(0)$ & $55,00(0)$ \\
\hline
\end{tabular}

${ }^{\mathrm{a} O s}$ valores entre parênteses apresentam a ordem em que foram realizados os ensaios; ${ }^{\mathrm{b}}$ Concentração de plastificante na solução formadora de filme (g plastificante/100 g proteína); ${ }^{\circ}$ Os valores entre parênteses são os códigos dos níveis das variáveis independentes e os experimentos de nos $15,16,17$ e 18 são os pontos centrais.

Os dados experimentais foram analisados com um modelo estatístico de $2^{\text {a }}$ ordem.

(Equação 1).

$$
\begin{aligned}
Y_{n}= & b_{0}+b_{1} x_{1}+b_{2} x_{2}+b_{3} x_{3}+b_{12} x_{1} x_{2}+b_{13} x_{1} x_{3}+b_{23} x_{2} x_{3} \\
& b_{123} x_{1} x_{2} x_{3}+b_{11} x_{1}^{2}+b_{22} x_{2}^{2}+b_{33} x_{3}^{2}
\end{aligned}
$$


Onde $b_{n}$ são os parâmetros do modelo, $\mathrm{Y}_{n}$ é a variável dependente e $\mathrm{x}_{\mathrm{k}}$ são as variáveis independentes. Este modelo foi ajustado aos pontos experimentais e o nível de significância do modelo foi analisado por meio dos coeficientes de correlação $\left(\mathrm{R}^{2}\right)$ e do teste F. Estas análises foram realizadas com o emprego do programa Statistica 5.0.

\section{Caracterização dos filmes}

\section{Espessura}

A espessura dos filmes foi determinada com um micrômetro (Modelo Tesa, Suíça), e calculada como a média de 15 medidas longitudinais e 10 medidas transversais (CUQ et al., 1995).

\section{Solubilidade}

Amostras do filme, cortadas na forma de círculos com $2 \mathrm{~cm}$ de diâmetro, previamente pesadas e de umidade conhecida, foram imersos em $50 \mathrm{ml}$ de água contendo azida sódica $(0,02 \% \mathrm{p} / \mathrm{v})$, a $25^{\circ} \mathrm{C} /$ 24 horas, sob agitação esporádica. A solubilidade dos filmes foi expressa em termos de matéria seca solubilizada (GONTARD; GONTARD; CUQ, 1992).

\section{Opacidade aparente}

A opacidade aparente dos filmes foi determinada utilizando-se um espectrofotômetro (Modelo DUSpectrophotometer, Beckman, USA). Os valores da opacidade aparente foram calculados como a área sob a curva de absorbância versus comprimento de onda, obtidas entre 400 e $800 \mathrm{~nm}$ para cada filme (GONTARD; GONTARD; CUQ, 1992).

\section{Permeabilidade ao vapor de água}

Para a determinação da permeabilidade ao vapor de água, amostras de filmes foram fixadas, hermeticamente, em células de permeação de vidro contendo sílica gel em seu interior ( $0 \%$ UR), com abertura circular com diâmetro de $34 \mathrm{~mm}$, correspondendo à área do filme exposta para troca. As células foram pesadas diariamente, em uma balança semi-analítica (Marte, AS2000, $\pm 0,01 \mathrm{~g}$ ) durante 8 dias.

A permeabilidade do vapor de água (Pva) foi calculada empregando-se a Equação (2).

$$
P v a=\frac{g}{t * A} * \frac{x}{\Delta p}
$$

Onde $A$ é a área de permeação $\left(9,1 \mathrm{~cm}^{2}\right)$, x é a espessura média dos filmes, e $\Delta \mathrm{P}$ é a diferença de pressão de vapor de água entre o ambiente contendo sílica gel (0) e água pura (2643 $\mathrm{Pa}$, a $\left.22^{\circ} \mathrm{C}\right)$. O termo $\mathrm{g} / \mathrm{t}$ foi calculado por regressão linear com os dados de ganho de peso $(\mathrm{g})$ da célula em função do tempo de condicionamento $(\mathrm{h})$.

\section{Propriedades mecânicas - força e deformação na} ruptura

A força e a deformação na ruptura foram determinadas em testes de perfuração, utilizandose um texturômetro TA.XT2 (SMS), com sensor cilíndrico de $3 \mathrm{~mm}$ de diâmetro movendo-se a 1,0 mm/s (GONTARD; GONTARD; CUQ, 1992). Os valores de força $(\mathrm{N})$ e deslocamento da sonda (\%) no ponto de ruptura foram registrados diretamente das curvas de força versus deslocamento da sonda, registradas pelo software "Texture expert" V 1.0 (Stable Micro Systems). Esses testes foram realizados a $25^{\circ} \mathrm{C}$ e UR entre 50 e $65 \%$.

\section{Resultados e Discussão}

A espessura média dos filmes foi de $0,040 \pm 0,005$ mm. O baixo desvio padrão calculado pode sugerir que o controle da espessura foi muito bom (SOBRAL, 2000). Em geral, todos os filmes formados se apresentaram com boa aparência, 
translúcidos, de fácil manuseio e com bom aspecto tátil, exceto para os filmes formados em $\mathrm{pH}$ 2,5 e em temperatura baixa $\left(35^{\circ} \mathrm{C}\right)$, condições em que se observou certa dificuldade na formação dos filmes.

Os resultados experimentais das caracterizações das propriedades dos filmes estão apresentados na Tabela 2. De acordo com os resultados das análises de variância, foi possível estabelecer modelos significativos (Tabela 3) para força (Y1) e deformação (Y2) na ruptura, solubilidade (Y3) e permeabilidade ao vapor de água (Y5), considerando-se que os valores de $\mathrm{p}$ e F calculados foram superiores aos valores de $\mathrm{F}$ tabelados a um nível de $80 \%$ de confiança. O modelo obtido com os dados de opacidade (Y4) não foi significativo.

Tabela 2. Valores médios da força na ruptura, deformação na ruptura, solubilidade, opacidade e permeabilidade ao vapor de água dos biofilmes, segundo o delineamento experimental.

\begin{tabular}{ccccccccc}
\hline \multicolumn{4}{c}{ Variáveis independentes } & \multicolumn{5}{c}{ Variáveis dependentes } \\
\hline $\begin{array}{c}\mathrm{N}^{\mathrm{o}} \\
\text { Experimento }^{\mathrm{a}}\end{array}$ & $\mathrm{X}_{1}(\mathrm{Cp})$ & $\mathrm{X}_{2}(\mathrm{pH})$ & $\mathrm{X}_{3}(\mathrm{~T})$ & $\mathrm{Y}_{1}(\mathrm{~F})$ & $\mathrm{Y}_{2}(\mathrm{D})$ & $\mathrm{Y}_{3}(\mathrm{~S})$ & $\mathrm{Y}_{4}(\mathrm{O})$ & $\mathrm{Y}_{5}(\mathrm{Pva})$ \\
$* 10^{10}$ & & & & & & \\
\hline $01(16)$ & $55,06(-1)$ & $2,7(-1)$ & $43,09(-1)$ & 2,15 & 10,20 & 18,72 & 81,96 & 2,54 \\
$02(15)$ & $69,94(1)$ & $2,7(-1)$ & $43,09(-1)$ & 2,28 & 17,94 & 15,40 & 153,20 & 4,17 \\
$03(14)$ & $55,06(-1)$ & $3,3(1)$ & $43,09(-1)$ & 1,61 & 13,87 & 19,66 & 187,40 & 1,86 \\
$04(13)$ & $69,94(1)$ & $3,3(1)$ & $43,09(-1)$ & 1,36 & 13,96 & 9,03 & 174,70 & 2,19 \\
$05(12)$ & $55,06(-1)$ & $2,7(-1)$ & $66,90(1)$ & 1,86 & 11,41 & 16,61 & 135,00 & 3,46 \\
$06(11)$ & $69,94(1)$ & $2,7(-1)$ & $66,90(1)$ & 1,37 & 13,76 & 14,22 & 113,70 & 2,30 \\
$07(10)$ & $55,06(-1)$ & $3,3(1)$ & $66,90(1)$ & 1,28 & 17,91 & 12,63 & 149,30 & 2,93 \\
$08(09)$ & $69,94(1)$ & $3,3(1)$ & $66,90(1)$ & 1,43 & 12,98 & 9,18 & 184,60 & 2,55 \\
$09(05)$ & $50,00(-1,68)$ & $3,0(0)$ & $55,00(0)$ & 2,45 & 12,17 & 27,65 & 174,40 & 1,88 \\
$10(07)$ & $75,00(1,68)$ & $3,0(0)$ & $55,00(0)$ & 1,92 & 12,88 & 22,42 & 178,20 & 2,05 \\
$11(06)$ & $62,50(0)$ & $2,5(-1,68)$ & $55,00(0)$ & 2,37 & 13,90 & 18,33 & 97,65 & 2,41 \\
$12(08)$ & $62,50(0)$ & $3,5(1,68)$ & $55,00(0)$ & 1,20 & 15,43 & 16,56 & 176,10 & 1,93 \\
$13(18)$ & $62,50(0)$ & $3,0(0)$ & $35,00(-1,68)$ & 1,73 & 10,70 & 19,36 & 116,50 & 2,54 \\
$14(17)$ & $62,50(0)$ & $3,0(0)$ & $75,00(1,68)$ & 1,25 & 12,98 & 2,42 & 11,70 & 2,18 \\
$15(01)$ & $62,50(0)$ & $3,0(0)$ & $55,00(0)$ & 2,17 & 14,24 & 24,46 & 114,80 & 1,70 \\
$16(02)$ & $62,50(0)$ & $3,0(0)$ & $55,00(0)$ & 1,75 & 12,12 & 24,86 & 101,10 & 1,74 \\
$17(03)$ & $62,50(0)$ & $3,0(0)$ & $55,00(0)$ & 2,43 & 12,93 & 24,81 & 113,20 & 1,36 \\
$18(04)$ & $62,50(0)$ & $3,0(0)$ & $55,00(0)$ & 2,73 & 13,04 & 25,53 & 157,50 & 1,73 \\
\hline
\end{tabular}

${ }^{a}$ Os valores entre parênteses apresentam a ordem em que foram realizados os ensaios; Experimentos de nos 15, 16, 17 e 18 são os pontos centrais; $\mathrm{X}_{1}(\mathrm{Cp})$-concentração do plastificante (\%, g/100 g proteína seca); $\mathrm{X}_{2}(\mathrm{pH})$-pH da solução filmogênica; $\mathrm{X}_{3}(\mathrm{~T})$-temperatura da solução filmogênica $\left({ }^{\circ} \mathrm{C}\right) ; \mathrm{Y}_{1}(\mathrm{~F})$-força na ruptura $(\mathrm{N})$; $\mathrm{Y}_{2}(\mathrm{D})$-deformação na ruptura (\%), $\mathrm{Y}_{3}(\mathrm{~S})$-solubilidade (\%, b.s.), $\mathrm{Y}_{4}(\mathrm{O})$-opacidade (Ua.nm) e $\mathrm{Y}_{5}(\mathrm{Pva})$-permeabilidade. ao vapor de água $\left(\mathrm{mol}^{*} \mathrm{~m} / \mathrm{s}^{*} \mathrm{~m}^{2 *} \mathrm{~Pa}\right)$ são as variáveis dependentes.

A seguir, serão apresentados e discutidos os resultados na forma de superfície de respostas, obtidos com os modelos estatísticos com parâmetros significativos, isto é, os parâmetros não significativos (Tabelas 3) não foram utilizados na obtenção desses gráficos. 
Tabela 3. Coeficientes de regressões e análises de variância utilizando o planejamento completo $2^{3}$ de um polinômio de $2^{\mathrm{a}}$ ordem para cinco variáveis respostas sob as diferentes condições de formação do filme de espessura média $40 \mu \mathrm{m}$.

\begin{tabular}{|c|c|c|c|c|c|}
\hline \multirow[b]{2}{*}{ Coeficientes } & \multicolumn{5}{|c|}{ Variáveis dependentes ${ }^{\mathrm{a}}$} \\
\hline & $\begin{array}{l}\text { Força } \\
(\mathrm{N})\end{array}$ & $\begin{array}{l}\text { Deformação } \\
(\%)\end{array}$ & $\begin{array}{c}\text { Solubilidade } \\
(\%)^{\mathrm{b}}\end{array}$ & $\begin{array}{l}\text { Opacidade } \\
\text { (Ua.nm) }\end{array}$ & $\begin{array}{c}\text { Permeabilidade }\left(10^{-10}\right) \\
\left(\mathrm{mol}^{*} \mathrm{~m} / \mathrm{s}^{*} \mathrm{~m}^{2 * \mathrm{~Pa})}\right.\end{array}$ \\
\hline & $\mathrm{Y}_{1}^{\mathrm{a}}$ & $\mathrm{Y}_{2}$ & $\mathrm{Y}_{3}$ & $\mathrm{Y}_{4}$ & $\mathrm{Y}_{5}$ \\
\hline $\mathrm{B}_{0}$ & $2,21^{*}$ & $8,87^{*}$ & $25,05^{*}$ & $125,34^{*}$ & $1,60^{*}$ \\
\hline \multicolumn{6}{|l|}{ Linear } \\
\hline $\mathrm{Cp}$ & $-0,28^{* *}$ & $0,18^{* * *}$ & $-2,09^{*}$ & & \\
\hline $\mathrm{pH}$ & & $0,21^{* *}$ & $-1,27^{*}$ & $25,20^{*}$ & $-0,27^{*}$ \\
\hline $\mathrm{T}$ & & & $-2,83^{*}$ & & \\
\hline \multicolumn{6}{|l|}{ Interações } \\
\hline $\mathrm{Cp} \times \mathrm{pH}$ & & $-0,66^{*}$ & $-1,04^{*}$ & & \\
\hline Cp x T & & $-0,45^{*}$ & $1,01^{*}$ & & $-0,43^{*}$ \\
\hline $\mathrm{pH} \times \mathrm{T}$ & & $0,24^{* * *}$ & $-0,45^{* *}$ & & $0,30^{*}$ \\
\hline \multicolumn{6}{|l|}{ Quadrático } \\
\hline $\mathrm{Cp} \times \mathrm{Cp}$ & & & $-0,59^{*}$ & $19,40^{* *}$ & $0,24^{*}$ \\
\hline $\mathrm{pH} \times \mathrm{pH}$ & $-0,18^{* * *}$ & $0,29^{*}$ & $-3,27^{*}$ & & $0,62^{*}$ \\
\hline $\mathrm{T} \times \mathrm{T}$ & $-0,29^{* *}$ & & $-5,59^{*}$ & & $0,37^{*}$ \\
\hline $\begin{array}{l}\text { Coeficiente de } \\
\text { correlação }\end{array}$ & 0,85 & 0,93 & 0,94 & 0,80 & 0,87 \\
\hline $\mathrm{F}_{\text {calculado }}$ & 8,78 & 11,03 & 6,83 & - & 5,60 \\
\hline $\mathrm{F}$ & $1,83_{(80 \%, 4,13)}$ & $1,83_{(80 \%, 6,11)}$ & $2,56_{(90 \%, 9,8)}$ & - & $2,39_{(90 \%, 6,11)}$ \\
\hline
\end{tabular}

Valores estatisticamente significativos: ${ }^{*} \mathrm{p}>95 \% ;{ }^{* *} \mathrm{p}>90 \%$ e ${ }^{* * *} \mathrm{p}>80 \%$ de confiança.

${ }^{a} Y_{1}, Y_{2}, Y_{3}, Y_{4}$ e $Y_{5}$ são as variáveis dependentes.

b(\%, b.s).

\section{Propriedades mecânicas}

\section{Força na ruptura}

A força na ruptura, propriedade que exprime a resistência do material à perfuração, atingiu um máximo de aproximadamente $2,5 \mathrm{~N}$, quando a $\mathrm{SF}$ foi preparada a $55^{\circ} \mathrm{C}$ e com $\mathrm{pH}=2,7$ (Figura 1). Pode-se observar que a força na perfuração caiu para 0,5 $\mathrm{N}$ quando o $\mathrm{pH}$ foi aumentado para 3,3, como conseqüência do forte efeito dessa variável. Observou-se também efeito significativo da temperatura, porém, de menor importância (Tabela 3). O efeito do $\mathrm{pH}$ pode ser explicado por possíveis rearranjos estruturais nas proteínas causados pela variação do $\mathrm{pH}$, que tem como conseqüência, uma exposição de grupos funcionais polares, dos resíduos de aminoácidos, permitindo interações diferenciadas entre as macromoléculas (CUQ et al., 1995). Em outras palavras, pode-se considerar que esse efeito do $\mathrm{pH}$ sobre a resistência dos filmes pode ser explicado pela solubilidade das proteínas (MONTERREY-QUINTERO; SOBRAL, 1999). Condições que favoreçam o aumento de cargas positivas ou negativas, como a alteração do $\mathrm{pH}$, aumentam a solubilidade, e a maior solubilidade das proteínas na SF favorece a interação intermolecular incrementando as propriedades mecânicas dos filmes (CUQ et al., 1995; MONTERREY-QUINTERO; SOBRAL, 1999). 
Figura 1. Efeito do $\mathrm{pH}$ e temperatura de formação da solução filmogênica filme sobre a força na ruptura, mantendo-se constante a concentração de plastificante, em $62,5 \%(\mathrm{~g} / 100 \mathrm{~g}$ de proteína) e a concentração de proteína, em $1 \%(\mathrm{p} / \mathrm{p})$.

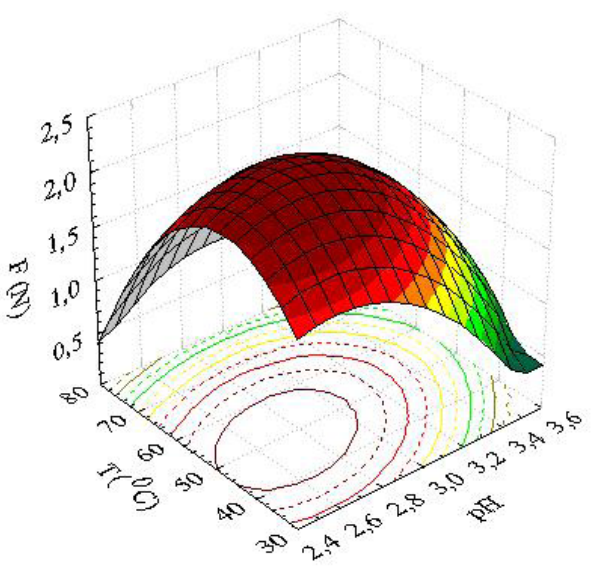

Por outro lado, segundo Ziegler e Acton (1984), o mecanismo de gelatinização das frações de miosina e actomiosina ocorre em duas fases: em temperaturas abaixo de $50^{\circ} \mathrm{C}$ ocorre desnaturação protéica, enquanto que acima de $55^{\circ} \mathrm{C}$ parece ocorrer agregação rápida, seguida da gelatinização. Isso pode explicar o efeito da temperatura (tratamento térmico da SF) sobre a força na ruptura, cujo máximo ficou em torno de $50^{\circ} \mathrm{C}$. Esse comportamento em relação à temperatura de tratamento térmico tem sido observado por outros autores que trabalham com proteínas similares (IWATA et al., 2000; PEREZ-GAGO; KROCHTA, 2001; GARCIA; SOBRAL, 2005). Esses autores alegaram que o tratamento térmico, até um determinado ponto, pode favorecer a formação de pontes de sulfeto entre cadeias peptídicas adjacentes, aumentando, conseqüentemente, a resistência do material. Por outro lado, o aumento da temperatura acima desse ponto, favorece a desnaturação da proteína, escondendo grupos sufidrilas livres, isto é, indisponibilizando-os para formações de pontes de sulfeto (MONAHAN; GERMAN; KINSELLA, 1995).
Os filmes de PML produzidos com a melhor formulação da SF deste trabalho apresentaram valores de força na ruptura menores que ao determinado por Sobral, Ocuno e Savastano Júnior (1998), para filmes a base de proteínas miofibrilares de carne bovina preparadas com outra técnica: em torno de 5,5N ( $\mathrm{pH}=2,7 ; \mathrm{Cp}=1 \% ; \mathrm{Cp}=60 \%$ e $\mathrm{T}=50^{\circ} \mathrm{C}$ ). Filmes à base de proteínas miofibrilares de sardinha (Sardina pilchardus), produzidos por Cuq et al. (1996a), também foram mais resistentes: aproximadamente $4,5 \mathrm{~N}(\mathrm{pH}=3,0 ; \mathrm{Cp}=2 \% ; \mathrm{Cp}=$ $35 \%$ ), para espessura equivalente.

\section{Deformação na ruptura}

A deformação na ruptura foi influenciada pelo $\mathrm{pH}$ e concentração do plastificante com domínios que se invertem. O clássico comportamento em relação ao plastificante, ou seja, aumento da deformação na ruptura como conseqüência do aumento da concentração do plastificante (MONTERREYQUINTERO; SOBRAL, 1999; PASCHOALICK et al., 2003; CHIRITA, 2008; McHUGH; KROCHTA, 1994) foi observado apenas na região de baixo valor de $\mathrm{pH}$ (Figura 2). As interações intermoleculares, formadas por ligações dissulfídicas devido aos grupos sulfidrilas (-SH) das moléculas de miosina, contribuem para uma alta interação cooperativa entre as moléculas de proteína, aumentando a coesividade da rede protéica e, conseqüentemente, diminuindo a sua flexibilidade (CUQ et al., 1995). Entretanto, o glicerol, plastificante hidrofílico, quando incorporado a essa rede de proteína, colocase entre os peptídeos, reduzindo a proximidade entre as cadeias de proteínas e, conseqüentemente, facilitando a mobilidade molecular (MONTERREYQUINTERO; SOBRA1, 1999; PASCHOALICK et al., 2003; CHIRITA, 2008; McHUGH; KROCHTA, 1994). 
Figura 2. Efeito combinado do $\mathrm{pH}$ e da concentração do plastificante $(\mathrm{Cp})$ da solução formadora de filme sobre a deformação na ruptura dos filmes, com concentração de proteína $1 \%(\mathrm{p} / \mathrm{p})$ e mantendo-se a temperatura constante em $\mathrm{T}=55^{\circ} \mathrm{C}$.
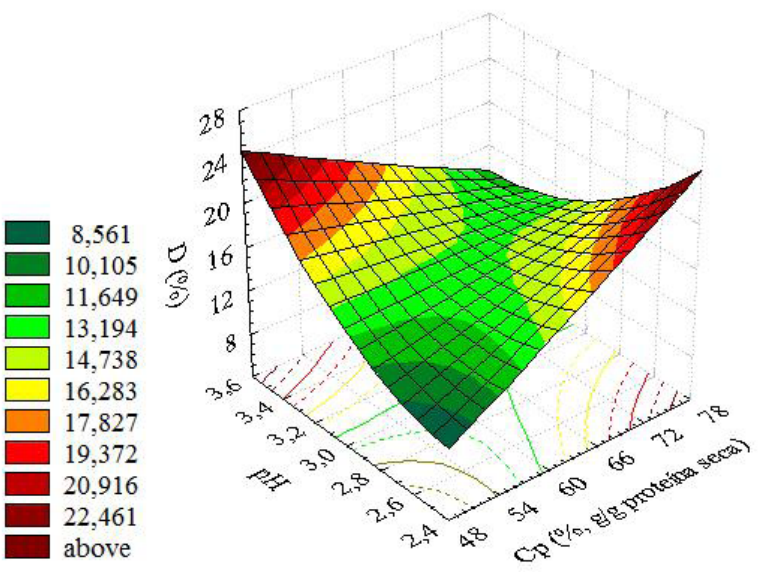

Por outro lado, em valores de $\mathrm{pH}$ maiores, observou-se comportamento inverso, ou seja, o aumento da concentração de glicerol propiciou uma diminuição nos valores de deformação na ruptura (Figura 2). Essa inversão no comportamento pode ter ocorrido em virtude da mudança do grau de ionização dos aminoácidos ionizáveis aminos protonados, com o aumento do $\mathrm{pH}$, isto é tendendo para o $\mathrm{pI}(5,2-5,3)$ das proteínas.

Observou-se a ocorrência de maiores valores de deformação na ruptura nos dois domínios descritos anteriormente (baixo $\mathrm{pH}$ e alta $\mathrm{Cp}$ e alto $\mathrm{pH}$ e baixa Cp): 17,94 e 17,91\%. A deformação na ruptura desses filmes foi superior a de outros filmes a base de proteínas miofibrilares (SOBRAL; OCUNO; SAVASTANO JÚNIOR, 1998; MONTERREYQUINTERO; SOBRAL, 1999; PASCHOALICK et al., 2003; SOBRAL, 2000).

\section{Solubilidade}

Todas as variáveis independentes apresentaram efeitos significativos sobre a solubilidade (Tabela 3). Pode-se observar a ocorrência de um ótimo da propriedade solubilidade, com valor máximo de cerca de $28 \%$, ocorrendo no plano central (Figura
3), isto é, com $\mathrm{Cp}=50 \%, \mathrm{pH}=3,0$ e $\mathrm{T}=55^{\circ} \mathrm{C}$. Em contrapartida, o menor o menor valor da solubilidade foi de 2,4\% ( $\mathrm{Cp}=62,5 \%, \mathrm{pH}=3,0$ e $\mathrm{T}=75^{\circ} \mathrm{C}$, Tabela 2 ).

Figura 3. Efeito combinado da temperatura e do $\mathrm{pH}$ da solução filmogênica sobre a solubilidade dos filmes, com a concentração de proteína $1 \%(\mathrm{p} / \mathrm{p})$, mantendo-se a concentração de plastificante constante em $62,5 \%$.

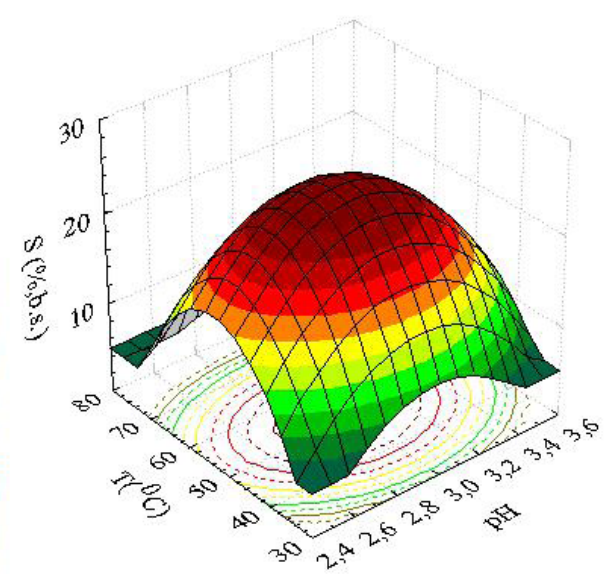

A solubilidade do filme é conseqüência da perda da integridade estrutural dos filmes, bem como da hidrofilicidade do plastificante, e do grau de desnaturação da proteína. A solubilidade dos filmes produzidos neste trabalho, de modo geral, apresentou valores baixos (2 a 28\%), comparados a outros filmes. Cuq et al. (1995) e MonterreyQuintero e Sobral (1999) observaram, em filmes a base de PM de sardinha do Atlântico e tilápiado-Nilo, valores entre $33-47 \%$ e $12,3-19,5 \%$, respectivamente. A diferença de solubilidade entre os filmes a base de proteínas miofibrilares de peixe (sardinha do Atlântico e tilápia-do-Nilo) e bovina se deve, provavelmente, às diferenças entre espécies, processo de extração, estado pré-rigor e post-rigor em que foram extraídas, e também a temperatura em que foi realizada a solução formadora de filme.

Do ponto de vista prático, a baixa solubilidade dos filmes, a base de proteínas miofibrilares de músculo bovino, permite visualizar um grande potencial de aplicação em alimentos com alto teor 
de umidade, inclusive, como embalagem ativa (MORAES et al., 2011). A integridade dos filmes durante o teste de solubilidade permite sugerir que a matriz protéica do filme não foi totalmente desestabilizada, ou seja, as interações moleculares intra e intercadeias permaneceram praticamente intactas, e, que, somente monômeros, pequenos peptídeos, substancias não protéicas e pequena quantidade de plastificante foram solubilizadas.

\section{Opacidade aparente}

Os filmes de PML produzidos neste trabalho apresentaram-se relativamente opacos, com valores entre 82 e 187 Ua.nm para $\mathrm{Cp}, \mathrm{pH}$ e T $(55,06 ; 2,7$ e 43,09 e 55,06; 3,3 e 43,09, respectivamente) (Tabela 2). Na Figura 4 se apresenta a opacidade em função da concentração de plastificante e pH. Observou-se uma queda acentuada da opacidade com a diminuição do $\mathrm{pH}$, e a ocorrência de valores mínimos com filmes com $62,5 \%$ de glicerol. Esse comportamento pode ter sido conseqüência do grau iônico dos amino ácidos, que afeta a solubilidade das proteínas. Monterrey-Quintero e Sobral (2000) observaram que a solubilidade das proteínas miofibrilares de Tilápia do Nilo aumentou com a redução do $\mathrm{pH}$. Assim, o filme obtido com proteínas na região de maior solubilização implicou em menor opacidade, conforme se pode observar na Figura 4.

Os valores de opacidade determinados neste trabalho foram superiores aos de filmes a base de proteínas miofibrilares de sardinha do Atlântico (CUQ et al., 1995) e de Tilápia do Nilo, cujo valor médio foi de 25 Abs.nm (MONTERREYQUINTERO; SOBRAL, 1999), porém inferiores aos de filmes a base de glúten de trigo, com opacidade aproximada de 250 Ua.nm (GONTARD; GONTARD; CUQ, 1992). A causa provável das diferentes opacidades entre os filmes a base de proteínas de peixe e de carne bovina, devese principalmente ao tipo de músculo: branco e vermelho, respectivamente, ao estado em que as proteínas miofibrilares foram extraídas, e também às condições de processamento dos filmes. A característica de opacidade dos filmes produzidos neste trabalho sugere que eles podem apresentar boa barreira à luz, uma vez que alta opacidade implica na redução da passagem da luz através do material.

Figura 4. Efeito combinado do pH e da concentração do plastificante na solução filmogênica, sobre a opacidade dos filmes com a concentração de proteína $1 \%(\mathrm{p} / \mathrm{p})$, mantendo a temperatura constante em $55^{\circ} \mathrm{C}$.

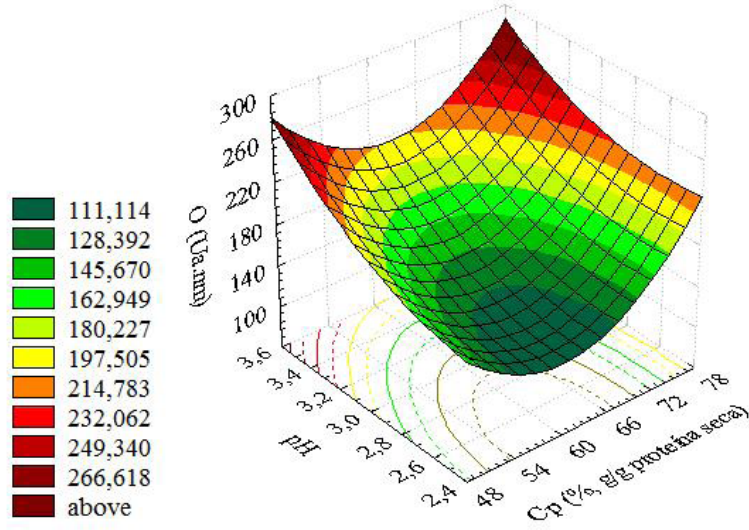

\section{Permeabilidade ao vapor de água}

Analisando-se as superfícies de resposta da interação entre $\mathrm{pH}$ e $\mathrm{Cp}$ (Figura 5a) e Temperatura e $\mathrm{pH}$ (Figura 5b), observa-se que existe um valor mínimo (em torno de 1,7.10-10 $\mathrm{mol} . \mathrm{m} / \mathrm{s} \cdot \mathrm{m}^{2} . \mathrm{Pa}$ ) ocorrendo com $\mathrm{Cp}=60 \%, \mathrm{pH}=3,1$ e $\mathrm{T}=50^{\circ} \mathrm{C}$. Fora desse domínio, os maiores valores da permeabilidade ao vapor de água provavelmente estão relacionados com a abertura da macromolécula, e a entrada facilitada das moléculas de glicerol na rede protéica, que, posteriormente, provoca uma fácil difusão das moléculas de água através dos filmes (STUCHELL; KROCHTA, 1994; McHUGH; KROCHTA, 1994; PARK et al., 1993). A título de curiosidade, observase que o maior valor de Pva $\left(4,17.10^{-10} \mathrm{~mol} . \mathrm{m} / \mathrm{s}\right.$. $\mathrm{m}^{2} . \mathrm{Pa}$ ) foi encontrado com $\mathrm{Cp}=69,94 \% ; \mathrm{pH}=2,7 \mathrm{e}$ $\mathrm{T}=43,09^{\circ} \mathrm{C}$.

Ao se comparar valores de permeabilidade ao vapor de água obtidos com $\mathrm{SF}$ em $\mathrm{pH}$ próximo a 3,6 , verifica-se que esses são bem menores que os 
valores determinados em $\mathrm{pH}=2,5$. Essa diferença é atribuída aos diferentes efeitos provocados pelo $\mathrm{pH}$ na macromolécula. Quando o $\mathrm{pH}$ está próximo de 3,6 tem-se uma maior solubilidade das proteínas, a estrutura protéica permanece intacta, até aproximadamente $50^{\circ} \mathrm{C}$, mas para temperaturas mais elevadas há modificações na estrutura protéica. Ao se elevar a temperatura da solução formadora de filme, se favorece uma maior incorporação de plastificante devido a abertura da cadeia de proteína, cuja estrutura e organização molecular modifica, com conseqüente aumento do volume livre que diminui a densidade de interações. Adicionalmente, diminui-se a densidade de interações tornando a rede mais frouxa, e, portanto, mais solúvel devido o aumento de grupos hidrofílicos expostos, que irão interagir com a molécula de glicerol, intensificando a afinidade pela água, e aumentando a permeabilidade ao vapor de água $(\mathrm{McHUGH}$; KROCHTA, 1994; CHERIAN et al., 1995; CUQ et al., 1997a; OCUNO; SOBRAL, 1998). Em pH=2,5, ocorre a desnaturação das moléculas de miosina e subunidades próximas a $50^{\circ} \mathrm{C}$, assim como da actina (actomiosina e fragmentos de actina) (SOBRAL et al., 1997).

Figura 5. Efeito combinado na SF com concentração de proteína $1 \%(\mathrm{p} / \mathrm{p})$ sobre a permeabilidade dos filmes: (a), Cp $\left(\%, \mathrm{~g} / 100 \mathrm{~g}\right.$ proteína seca) e $\mathrm{pH} ;$ mantendo-se constante a temperatura $\left(50^{\circ} \mathrm{C}\right) ;(\mathrm{b}), \mathrm{T}^{\circ} \mathrm{C}$ e $\mathrm{pH}$, mantendo-se constante a concentração do plastificante $(62,5 \%)$.

A

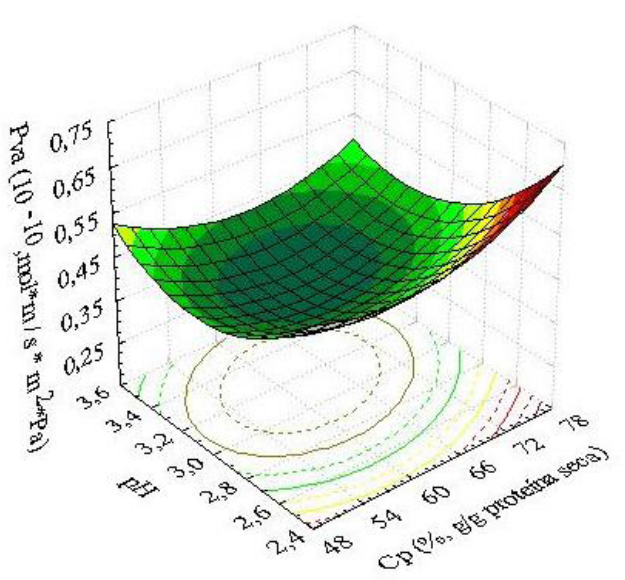

B

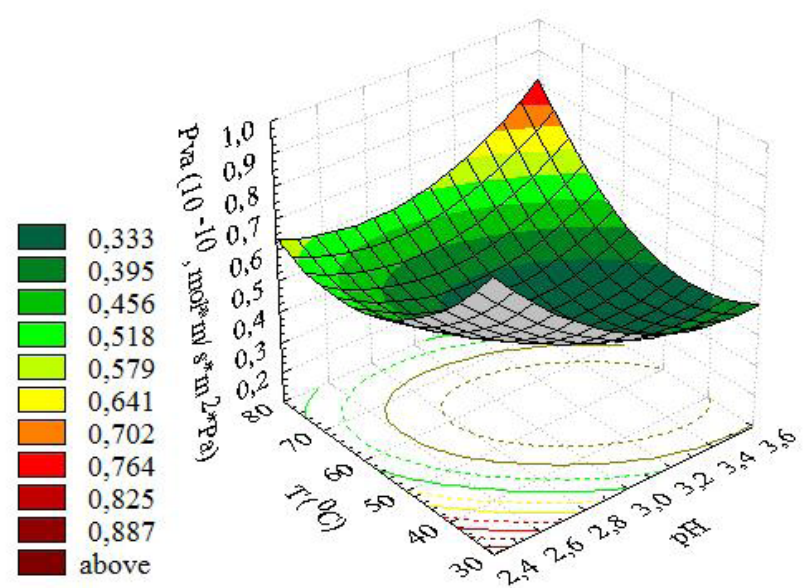

\section{Conclusão}

$\mathrm{O}$ pH da solução filmogênica (SF) afetou significativamente todas as propriedades físicas estudadas. $\mathrm{O}$ pH influencia a estrutura dos peptídeos afetando, conseqüentemente, sua solubilidade em água. Dessa forma, as interações entre cadeias adjacentes de peptídeos, e entre essas e o plastificante, são também influenciadas pelo $\mathrm{pH}$ da SF.

A temperatura do tratamento térmico da $\mathrm{SF}$ afetou significativamente a força na ruptura,

solubilidade e a permeabilidade ao vapor de água (Pva). Esse tratamento pode favorecer as interações intermoleculares via formação de pontes dissulfidicas, favorecendo as propriedades físicas que dependem disso, como as propriedades mecânicas e a Pva. Entretanto, o tratamento térmico muito intenso pode reverter esse efeito por alterações estruturais irreversíveis nas proteínas.

E finalmente, a concentração do glicerol afetou significativamente todas as propriedades estudadas, com exceção da força na ruptura, uma vez que o plastificante aumenta a mobilidade das 
macromoléculas, reduzindo suas interações, com conseqüências em todas as propriedades físicas. A não observação de efeito significativo sobre a opacidade dos filmes deve ser creditada à falta de ajuste, considerando que os valores de $\mathrm{p}$ e $\mathrm{F}$ não foram significativos.

\section{Agradecimento}

Ao CNPq pelas bolsas de SMAS e de pesquisador PJAS. À FAPESP pelos auxílios.

\section{Referências}

BARROS NETO, B. B.; SCARMINIO, I. S.; BRUNS, R. E. Planejamento e otimização de experimentos. 2. ed. Campinas: UNICAMP, 2005. 326 p.

CHEFTEL, J. C.; CUQ, J.-L; LORIENT, D. Proteinas alimentarias: bioquímica, propriedades funcionales, valor nutricional, modificaciones. Zaragoza: Acribia, 1989. $346 \mathrm{p}$.

CHERIAN, G.; GENNADIOS, A.; WELlER, C.; CHINACHOTI, P. Thermomechanical behavior of wheat gluten films: effect of sucrose, glycerin, and sorbitol. Cereal Chemistry, Manhattan, v. 72, n. 1, p. 1-6, 1995.

CHIRITA, M. Mechanical properties of collagen biomimetic films formed in the presence of calcium, silica and chitosan. Journal of Bionic Engineering, Changchun, v. 5, n. 2, p. 149-158, 2008.

CUQ, B.; AYMARD, C.; CUQ, J.-L.; GUILBERT, S. Edible packaging films based on fish myofibrillar proteins: Formulation and functional properties. Journal of Food Science, Chicago, v. 60, n. 6, p. 1369-1374, nov./ dez. 1995.

CUQ, B.; GONTARD, N.; CUQ, J.-L.; GUILBERT, S. Functional properties of myofibrillar protein-based biopackaging as affected by film thickness. Journal of Food Science, Chicago, v. 61, n. 3, p. 580-584, maio/jun. 1996a.

Rheological models for the mechanical properties of myofibrillar protein-based films. Journal of Agricultural and Food Chemistry, Washington, v. 44, p. 1116-1122, 1996b.

. Selected functional properties of fish myofibrillar protein-based films as affected by hydrophilic plasticizers. Journal of Agricultural Food Chemistry, Washington, v. 45 , n. 3, p. 622-626, 1997a.
CUQ, B.; GONTARD, N.; GUILBERT, S. Thermal properties of fish myofibrillar protein-based films as affected by moisture content. Polymer, Great Britain, v. 38, n. 10, p. 2399-2405, 1997 b.

GARCÍA, F. T.; SOBRAL, P. J. A. Effect of the thermal treatment of the filmogenic solution on the mechanical properties, color and opacity of films based on muscle proteins of two varieties of Tilapia. $L W T$, Zurique, v. 38, n. 3, p. 289-296, 2005.

GONTARD, N.; GONTARD, S.; CUQ, J.-L. Edible wheat gluten films: influence of the main process variables on film properties using response surface methodology. Journal of Food Science, Chicago, v. 57, n. 1, p. 190199, jan./fev. 1992.

IWATA, K.; ISHIZAKI, S.; HANDA, A.; TANAKA, M. Preparation and characterization of edible films from fish water-soluble proteins. Fisheries Science, Tóquio, v. 66, n. 2 , p. $372-378,2000$.

McHUGH, T. H.; KROCHTA, J. M. Sorbitol- vs glicerolplasticized whey protein edible films: integrated oxygen permeability and tensile property evaluation. Journal of Agricultural and Food Chemistry, Washington, v. 42, n. 4, p. 841-845, abr. 1994.

MONAHAN, F. J.; GERMAN, J. B.; KINSELLA, J. E. Effect of $\mathrm{pH}$ and temperature on protein unfolding and thiol/disulfide interchange reactions during heat-induced gelation of whey proteins. Journal of Agricultural and Food Chemistry, Washington, v. 43, n. 1, p. 46-52, 1995.

MONTERREY-QUINTERO, E. S.; SOBRAL, P. J. do A. Caracterização de propriedades mecânicas e óticas de biofilmes à base de proteínas miofibrilares de tilápiado-nilo usando uma metodologia de superfície-resposta. Ciência e Tecnologia de Alimentos, Campinas, v. 19, n. 2, p. 294-301, 1999.

Preparo e caracterização de proteínas miofibrilares de tilápia-do-Nilo para elaboração de biofimes. Pesquisa Agropecuária Brasileira, Brasília, v. 35, n. 1, p. 179-189, jan. 2000.

MORAES, A. R. F.; VIDIGAL, M. C. T. R.; SOARES, N. F. F.; MORAES, L. P.; MELO, N. R.; GONÇALVES, M. P. J. Desenvolvimento e avaliação de filme antimicrobiano aromatizado para aplicação em massa de pastel. Ciência Rural, Santa Maria, v. 41, n. 3, p. 537-543, mar. 2011.

OCUNO, D.; SOBRAL, P. J. A. Preparo de proteínas miofibrilares de carne e elaboração de biofilmes com dois tipos de ácidos: propriedades mecânicas. Brazilian Journal of Food Technology, Campinas, v. 1, n. 1/2, p. 44-52, jan./dez. 1998. 
PARK, H. J.; WELLER, C. L.; VERGANO, P. J.; TESTIN, R. F. Permeability and mechanical properties of cellulose-based edible films. Journal of Food Science, Chicago, v. 58, n. 6, p. 1361-1370, nov./dez. 1993.

PASCHOALICK, T. M.; GARCIA, F. T.; SOBRAL, P. J. do A.; HABITANTE, A. M. Q. B. Characterization of some functional properties of edible films based on muscle proteins of Nile Tilapia. Food Hydrocolloids, Lancaster, v. 17, n. 4, p. 419-427, 2003.

PEREZ-GAGO, M. B.; KROCHTA, J. M. Denaturation time and temperature effects on solubility, tensile properties, and oxygen permeability of whey protein edible films. Journal of Food Science, Chicago, v. 66, n. 5, p. 705-710, 2001.

SOBRAL, P. J. do A. Influência da espessura sobre certas propriedades de biofilmes à base de proteínas miofibrilares. Pesquisa Agropecuária Brasileira, Brasília, v. 35, n. 6, p. 1251-1259, 2000.

SOBRAL, P. J. do A.; OCUNO, D. Permeabilidade ao vapor de água de biofilmes à base de proteínas miofibrilares de carne. Brazilian Journal of Food Technology, Campinas, v. 3, n. 3, p. 11-16, 2000.

SOBRAL, P. J. do A.; MENEGALLI, F. C.; CARVALHO, R. A. de; SOUZA, S. M. A. de; QUINTERO, E.
S. M. Elaboração de filmes de proteínas para uso como impermeabilizante ou embalagem flexível. In: SEMINÁRIO INTERNACIONAL: TÓPICOS ESPECIAIS EM CIÊNCIA E TECNOLOGIA DE PROTEÍNAS, 1., 1997, Campinas. Anais... Campinas: ITAL, nov. 1997. p. 95-104.

SOBRAL, P. J. do A.; OCUNO, D.; SAVASTANO JÚNIOR, H. Preparo de proteínas miofibrilares de carne e elaboração de biofilmes com dois tipos de ácidos: propriedades mecânicas. Brazilian Journal of Food Technology, Campinas, v. 1, n. 1/2, p. 44-52, 1998.

SOUZA, S. M. A.; SOBRAL, P. J. A.; MENEGALLI, F. C. Extração de proteínas miofibrilares de carne bovina para elaboração de filmes comestíveis. Ciência Tecnologia de Alimentos, Campinas, v. 24, n. 4, p. 619626, dec. 2004.

STUCHELL, Y. M.; KROCHTA, J. M. Enzymatic treatments and thermal effects on edible soy protein films. Journal of Food Science, Chicago, v. 59, n. 6, p. 1332-1337, nov./dez. 1994.

ZIEGLER, G. R.; ACTON, J. C. Mechanisms of gel formation by proteins of muscle tissue. Food Technology, Chicago, v. 38, n. 5, p. 77-82, maio 1984. 
